Canadian Studies in Population 41, no. 1-2 (spring/summer 2014): 61-77

\title{
Childbearing among Canadian stepfamilies
}

\author{
Valerie Heintz-Martin ${ }^{1}$ \\ Céline Le Bourdais \\ Dana Hamplová
}

\begin{abstract}
This article analyses childbearing in stepfamilies in Canada, using the 2001 General Social Survey on family. It estimates the probability that stepfamily couples will give birth to a child according to the composition of the stepfamily, and then moves on to explore the factors that are associated with such an event. Particular attention is given to the type of union, parental status, and number of children of both partners. Contrary to past studies, this research is based not only on women's retrospective conjugal and parental histories but also on those reported by male respondents, and it controls for women's work status.
\end{abstract}

Keywords: stepfamilies, childbearing, men and women, Canada, event history analysis.

\section{Résumé}

Cet article analyse l'arrivée d'un enfant commun au sein des familles recomposées au Canada à partir d'une exploitation de l'Enquête sociale générale de 2001. Dans un premier temps, il estime la probabilité qu'ont les couples vivant en famille recomposée de donner naissance à un enfant en tenant compte de la composition de la famille. Dans un deuxième temps, il examine l'effet que différents facteurs, tels le type d'union, le statut parental et le nombre d'enfants de chacun des partenaires, exercent sur la survenue de cet événement. Contrairement aux études antérieures, l'analyse inclut non seulement les histoires conjugale et parentale rapportées par les femmes mais également celles des hommes, et elle tient compte du statut d'emploi des femmes.

Mots-clés : familles recomposées, naissances, hommes et femmes, Canada, analyse des transitions.

\section{Introduction}

In Canada, as in most western countries, family life has become increasingly unstable as couples tend to separate at a fast pace, even in the presence of young children (Bohnert 2011). Following the breakup of their first union, a growing number of men and women move on to enter new relationships, predominantly through cohabitation, and often with a partner who already has children. In this case, they form a stepfamily - a type of family that has become more common over the years (Sweeney 2010), and in which an increasing number of children are born, as a large fraction of stepfamily couples have at least one child together (Stewart 2002). Consequently, the analysis of fertility can no longer be reduced to that of childbearing within a first marriage, and it has to take account of the fact that a growing number of individuals have children with more than one partner.

1. Valerie Heintz-Martin, Families and Family Policies Department, German Youth Institute, Munich. Email: heintz-martin@dji.de; with Céline Le Bourdais, Department of Sociology, McGill University, Montreal. Email: celine.lebourdais@mcgill.ca; and Dana Hamplová, Institute of Sociology, ASCR \& Charles University, Prague. E-mail: dana.hamplova@soc.cas.cz. 
Reflecting this trend, numerous European and US studies have examined fertility behaviours following marital dissolution (Jefferies et al. 2000; Beaujouan and Solaz 2008; Brown 2000) and, more specifically, childbearing in stepfamilies (Vikat et al. 1999; Henz 2002; Prskawetz et al. 2002; Thomson and Li 2002; Vikat et al. 2004; Thomson 2004; Li 2006). This body of research mainly focused on whether childbearing in second unions or in stepfamilies is motivated by the same factors as fertility in general, and especially on whether the presence of children from a previous relationship influences the couple's risk of having a child together.

In spite of this renewed interest in the study of fertility, the effect of the presence of children prior to the formation of the couple on childbearing remains unclear. First, some researchers have controlled for the number of stepchildren in the analysis but did not pay attention to the composition of the family, that is, to the number of children that each partner had at the beginning of the stepfamily episode (Juby et al. 2001). Second, some studies have failed to take cohabiting stepfamily couples into consideration (Li 2006) or examined childbearing behaviours only when following marital disruption (Brown 2000; Jefferies et al. 2000), and thus excluded a large fraction of stepfamilies from the analysis (see Stewart 2001). Third, previous research has been based almost entirely on women's retrospective reproductive and conjugal histories, and has rarely taken men's fertility into account (for some exceptions, see Stewart 2002; Thomson and Li 2002), despite the need for "bringing men back" into the study of fertility, as argued by a rising number of scholars (e.g., Goldscheider and Kaufman 1996). Finally, to our knowledge, no research has included women's employment in the analysis, even though fertility has been shown to be strongly associated with women's labour market behaviour (Brewster and Rindfuss 2000) and given the high propensity of women living in stepfamilies to be working (Lapierre-Adamcyk and Le Bourdais 2008).

This study seeks to fill these gaps in the literature. More specifically, it examines childbearing in stepfamilies in Canada using the 2001 General Social Survey (GSS) on family. We first estimate the probability that stepfamily couples will give birth to a common child according to the detailed composition of the stepfamily. We use a broad definition of stepfamilies that includes all couples - married or cohabiting - who live with at least one child born from one of the two partners' prior relationship, including those formed following the birth of a child to a lone mother. Particular attention is given to the parental status and to the number of children that each partner has. Contrary to most previous research and to the only Canadian study of stepfamily childbearing based on the 1990 GSS (Juby et al. 2001), the analysis includes not only women's retrospective conjugal and parental histories but also those reported by male respondents. Moreover, we control for female employment, taking advantage of the retrospective employment histories that were collected in the GSS.

\section{Family composition and childbearing in stepfamilies}

In a seminal study of fertility published in 1985, Griffith and her colleagues reviewed the principal determinants of childbearing among couples, and further developed a set of hypotheses concerning the birth of first and second children among remarried couples (Griffith et al. 1985). According to these authors, the birth of the first child is generally valued for two reasons. First, it confers 'adult status' through parenthood on each individual, and second, it shows the partners' commitment to the union. In stepfamilies though, the first child born to the couple may provide parental status to neither partner, if both of them have children from a previous relation (Vikat et al. 1999). However, when only one partner brings children into the newly formed union, the birth of

a 'common' child could be strongly valued for legitimating in their parental role the man or woman 
Heintz-Martin et al.: Childbearing among Canadian stepfamilies

who, prior to this birth, was only involved as a stepparent in the family (Ambert 1986). In that sense, the risk of childbearing could be independent of the number of children present in the family, but closely linked to the stepfamily composition. Similarly, as argued by Griffith et al. (1985), the first child born to a stepfamily couple can be viewed as a signal of a commitment to the union and as "a symbol of the couple's relationship, expressing their commitment to each other" (Thomson and Li 2002: 1), irrespective of the number of children born from each partner's previous relationship. In addition, the birth of a common child creates a genetic link between all members of the stepfamily (Juby et al. 2001) and it has been shown to be positively associated with union stability (Wineberg 1992; Martin et al. 2011).

Moreover, the birth of a 'common' child might take on a special value among one-child stepfamilies. In Griffith et al.'s (1985) framework, the second child is valued primarily because it provides a sibling for the first child. Siblings are considered to be good for children as they provide companionship and help children learning to share with others (Vikat et al. 1999). The fact that the norm of two children per family still appears particularly strong is exemplified by the high proportion of women who have exactly two children (Bumpass 1984; see Thomson and Li 2002; Le Bourdais et al. 2013).

The first studies of fertility in stepfamilies originated primarily in the United States and were based almost exclusively on women's marital and reproductive histories (Griffith et al. 1985; Wineberg 1992). These studies found mixed results regarding the effect that the number of children from previous unions exerts on the probability to give birth to a child. Some studies showed that the number of children reduces the couple's risk of having a child together (Brown 2000; Buber and Prskawetz 2000; Wineberg 1990), whereas a large body of research conducted in the United States (Griffith et al. 1985), Sweden (Vikat et al. 1999), France (Toulemon 1997), and Canada (Juby et al. 2001) observed no such effect, reinforcing the idea of the unique value of a first shared birth for stepfamily couples (Thomson and Li 2002).

However, more recent studies argue for the necessity to take into account not only the number of children born in previous unions, but also to identify "whose children are whose" (Stewart 2002: 182). The fact that only the man, only the woman, or both partners bring children into the stepfamily seems to closely affect the probability that the couple will have a common child, as does the number of children itself. Most studies show that women's previous children reduce stepfamily fertility more strongly than men's children do (Vikat et al. 2004). For instance, Thomson and Li (2002) found that women's childlessness increases the risk of stepfamily couples to have a child together but that men's childlessness does not. Moreover, childless women have a high risk to give birth to a child even if their partners have two or more children, but the reciprocal does not hold true: the fact that the woman has two or more children significantly reduces the risk of childless men to have a child (Thomson 1997).

Two arguments have been advanced to account for the larger effect that women's rather than men's past fertility exerts on the propensity of stepfamily couples to have a child together. First, Thomson and Li (2002) invoke the idea that maternal status has a higher value than paternal status in western societies. Second, Vikat and his colleagues (2004) emphasize the role of children's residence following parental separation, namely the fact that children of separated or divorced parents are more likely to live with their mother than with their father (also see Juby et al. 2001). They conclude that the greater costs associated with raising resident as opposed to non-resident stepchildren mean that "the pre-union children of women are, on average, more costly to the couple than are the pre-union children of men" (Vikat et al. 2004: 3). Moreover, for women who are already mothers, having a child in the new union might also represent additional 
costs and responsibilities that they are not willing to take on, given that they are more likely than their partners to reside with the child in case of separation. In contrast, childless women who live with a man and his children might regard this situation as a sign of their partner's parental involvement and thus be encouraged to have a child who, in addition, will legitimate them in a parental role (Ambert 1986).

Vikat and his colleagues (2004) further suggest that family policies may play a role in the mixed findings observed across countries regarding the effects of women's and men's pre-union children on stepfamily childbearing. In a comparative study of stepfamily fertility in Finland and Austria, these authors found the gap separating the effects of women's and men's previous children to be narrower in the former than in the latter country. They argued that the less gender-egalitarian division of child-caring responsibilities and more difficult harmonization of family and work that exist in Austria could explain the larger impact of women's previous children relative to that of men's in the Austrian subsample.

Surprisingly though, Vikat et al.'s (2004) study did not attempt to control for the direct effect that women's employment could exert on the couple's fertility, net of the number of children that they had from previous relations. To our knowledge, no other research on stepfamily fertility did so, perhaps because of lack of information on women's employment histories. Yet, as previous work has shown, fertility and women's work appeared to be closely related, even though the relation between the two has evolved over time (Brewster and Rindfuss 2000). The collection of women's employment histories in the Canadian GSS will allow us to control for the impact of their work status on the risk to give birth to a child.

\section{Additional predictors of fertility in stepfamilies}

Other characteristics have been shown in past research to strongly influence childbearing in stepfamilies. Among these, the age of children from previous unions appears to play an important role in the decision of stepfamily couples to have a common child (Griffith et al. 1985, Juby et al. 2001). The risk of giving birth to a child was found to be higher among families in which the youngest child is a preschooler (Jefferies et al. 2000; Vikat et al. 2004). This result suggests that women might be unwilling to have long birth intervals that are likely to increase the time spent out of the labour force and shorten the adult-centered period of their life (Griffith et al. 1985; Jefferies et al. 2000).

Our analysis also includes the age of the woman as fecundity decreases with age (Beaujouan and Solaz 2008). In addition, the age difference between partners is taken into consideration, as it might affect the stepfamily couple's intention and ability to have a child together (Thomson and Li 2002). Furthermore, we control for the rank and type of union of the couple, as past research systematically showed that fertility is higher among married than cohabiting couples (Brown 2000; Jefferies et al. 2000; Le Bourdais and Lapierre-Adamcyk 2011). We also add a variable that distinguishes Quebec from other Canadian provinces, in order to take into account the higher level of institutionalisation of cohabiting unions in Quebec (Le Bourdais and Lapierre-Adamcyk 2004). The time period in which the episode was experienced is included in our models to control for the rise of conjugal instability over time and its impact on stepfamily formation (Juby et al. 2001). Finally, we also include respondents' highest level of education achieved, as it has been found to be linked to childbearing in previous Canadian and foreign studies (Brown 2000; Jefferies et al. 2000; Stewart 2002; Wu and Schimmele 2003). 
Heintz-Martin et al.: Childbearing among Canadian stepfamilies

\section{Data and Methods}

\section{Data}

Our analysis is based on the 2001 General Social Survey (GSS) on family conducted by Statistics Canada, which is representative of all Canadians aged 15 years and older who were not residing in the Yukon, Northwest Territories or Nunavut, and who were not living in an institution at the time of the interview. For the purpose of the survey, each province was divided into strata and separate samples were selected within each stratum. ${ }^{2}$ Respondents were contacted through means of Random Digit Dialling (RDD), a telephone sampling method. ${ }^{3}$ When a private household was reached, an algorithm was used to randomly select one household member (age 15 and older). The collection period extended from February through December 2001, and the overall response rate was 79 per cent (Statistics Canada 2001). ${ }^{4}$

The 2001 GSS interviewed a large sample of 24,310 male and female respondents, living in private households (Statistics Canada 2001). In addition to gathering detailed information on respondents' individual and household socioeconomic characteristics, the GSS collected their education and work histories. Respondents were also asked to record the history of all the unions (marriages or cohabiting unions) they had experienced and of all the children they had given birth to, adopted and/ or raised. For each union, the GSS gathered the date of beginning and, if applicable, the date and reason of ending of the union. ${ }^{5}$ For each child, the GSS collected the date of birth, as well as the date of arrival of adopted and step-children in the respondent's household; the date at which the child left the household for the last time was also recorded.

\section{Constructing the stepfamily episodes}

The information collected in the conjugal and parental histories allows the reconstruction of the stepfamily episodes that respondents have experienced through the course of their life. Here, the moment a respondent starts living with a married or cohabiting partner and with at least one child who is not the biological or adoptive children of both partners marks the beginning of the stepfamily episode. Reciprocally, the moment the union terminates, following separation, divorce or the death of the partner, or when the last stepchild leaves the respondent's home, marks the end of the episode.

The pathways to stepfamily formation are quite diverse. For some individuals, the stepfamily might be their first co-residential union while for others it might follow the dissolution (separation or death of partner) of a marriage or of a common-law relationship. Moreover, each episode might include children of one or both partners. Unfortunately, the GSS did not collect any information on the parental histories of respondents' partners. It is therefore impossible to determine with certainty whether the partner who started living with a respondent who had a child before the union is the biological parent of that child. Here, we consider that children born up to six

2. As a consequence of this multistage survey design, respondents have unequal probabilities of selection and sampling weights were computed and need to be used in order to account for both non-randomness and nonresponse (see below).

3. Households without telephones had no chances of being selected for the sample; Statistics Canada computed adjusted weights to ensure that the persons living in such households (who formed less than 2 per cent of the target population) were represented in the survey (Statistics Canada 2001).

4. The survey weights computed by Statistics Canada were adjusted to control for non-response.

5. The GSS collected the date (month and year) of each event, but the microdata file created by Statistics Canada provides the age (with a decimal) of respondents at each event. 
months prior to the beginning of a union belong to the union or, in other words, that they are the biological children of the couple; in such cases, the family unit is therefore not counted as a stepfamily. ${ }^{6}$ The lack of direct information on the partners' parental histories, along with the manner in which information on stepchildren was collected in the survey, ${ }^{7}$ also makes it quite unlikely that respondents mentioned stepchildren with whom they did not live. Consequently, our study probably includes predominantly respondents who resided with their stepchildren and excludes those who never lived with them on a regular basis. ${ }^{8}$ The number of respondents who ever lived with a partner who had children from a previous union thus risks to be underestimated, and more so among female respondents, given that fathers are less likely to live with their children after separation. Finally, one should note that the GSS did not gather information on children's living arrangements, which may have changed over the course of the episode, as the amount of time they spent in each of their separated parents' household fluctuated. We only know the date that children arrived in the respondents' life through birth, adoption or as stepchildren, as well as the date of their last departure from home. We cannot therefore account for temporal departures of children during the stepfamily episode.

Our analysis includes solely the first stepfamily episodes reported by respondents, which constitute the large majority of stepfamily episodes. ${ }^{9}$ In total, 2,389 respondents (1,511 females and 878 males) had experienced at least one episode of stepfamily life in their adulthood by the time of the survey (for more details about the constitution of the sample of stepfamily episodes, see Martin 2008). To take into account the decline of fecundity with age, we excluded from the analysis 232 episodes in which women were aged 43 or older at the time of the stepfamily formation (147 reported by women and 85 reported by men). In addition, we excluded 241 episodes that comprised only children aged 21 years or older at the formation of the stepfamily (116 reported by women and 125 reported by men). ${ }^{10}$ After excluding all cases in which the information on one or several covari-

6. The cut-off point retained to determine whether children born before the beginning of a union belong to this union or not varies across studies, from 0 month, in Prskawetz et al.'s (2002) research that treated as stepchildren all children born prior to the union, to 6 months (Griffith et al. 1985; Desrosiers et al. 1995) and even 11 or 12 months (Buber and Prskawetz 2000; Thomson 2004). We ran separate analyses using a 12-month cut-off point and found no changes in the results. We thus used 6 months as our cut-off point, as was done in previous Canadian studies (Desrosiers et al. 1995; Juby et al. 2001).

7. Respondents were first asked if they had "ever raised stepchildren." If so, they were further asked "in what month and year" did each stepchild "join their household" and, if applicable, "in what month and year" he or she "last left home."

8. For sake of coherence with the residential approach of stepparenthood imposed by the data, we considered the departure of the last stepchild from the respondent's household as marking the end of the stepfamily episode. This approach is also consistent with the hypothesis advanced to account for the larger effect of women's rather than men's past fertility on childbearing in stepfamilies, namely that children are more likely to reside with their mother.

9. This approach that distinguishes the family episodes by rank is the most common in the literature. It is based on the assumption that past experience influences subsequent behaviour and that the process underlying the first stepfamily episode might differ from that of ulterior episodes.

10. This decision was taken at an early stage of the research project that focuses on stepfamilies with dependent children. As noted by an anonymous reviewer, this strategy might have led to the exclusion from the analysis of some older men who partnered with younger women. However, we expect the effect of this exclusion to be relatively small, given the age distribution of women in such families; hence, a separate analysis of the existing stepfamilies at the time of the survey showed that the large majority of women living in a stepfamily that comprised only children aged 21 or older were at least 35 years old, and thus past prime reproductive ages (data not presented). 
Heintz-Martin et al.: Childbearing among Canadian stepfamilies

ates is missing, the final sample used in the regression models comprises 1,221 female and 658 male respondents who experienced at least one stepfamily episode. ${ }^{11}$

\section{Independent variables}

Time constant covariates

The stepfamily composition at the beginning of the episode is measured in three ways:

- The number of pre-union children in the stepfamily (3 categories): stepfamilies with one, two, or three and more children.

- Whose children are whose (3 categories): only the woman has children, only the man has children, and both partners have children.

- The number of children and whose children those are (6 categories): only the woman has 1 child, only the man has 1 child, only the woman has $2+$ children, only the man has $2+$ children, both partners have 1 child each, both partners have children for a total of $3+$ children.

The age of the woman at the beginning of the episode is introduced as a dummy variable in the models, to take into account that the risk of childbearing first increases and then decreases with age; it comprises four categories: 1) under 25 years; 2) 25 to 29 years; 3) 30 to 34 years; 4) 35 to 42 years. The age difference between partners distinguishes 1) couples in which the woman is 5 or more years younger than her partner; 2) those in which she is between less than 5 years younger and less than 2 years older; and 3) those in which the woman is 2 or more years older than her partner. The age of the youngest child present at the beginning of the episode identifies families with; 1) preschool age children (0-4 years); 2) elementary school children (5-11 years); and 3) adolescents (12-20 years). The bighest educational level completed by respondents at survey ${ }^{12}$ is coded into four categories: 1) less than high school degree; 2) high school diploma; 3) college degree; and 4) university degree. Finally, a region variable distinguishes Quebec respondents from those living elsewhere in Canada. ${ }^{13}$

Time-varying covariates

Three time-varying covariates are included into the analyses. The first one specifies the type of the union, which can change from common-law union to marriage if partners marry during the course of the episode. The second, which controls for the time period during which the stepfamily episode was experienced, is coded into the following four categories: 1) before 1970; 2) 1970-1979; 3) 1980-1989; and 4) 1990 and after. The last time-varying covariate indicates the employment status of women during the stepfamily episode; it is coded into three categories: 1) never worked for a period of at least six months; 2) working; and 3) not working (for those who had previously worked). For example, the work status of a woman can change from working, to not working, to working again, as a woman who was employed at the beginning of the episode, stops working and then re-enters the labour market during the course of the stepfamily episode. Given that the GSS collected only the retrospective histories of respondents, this last variable will be included solely in the analysis based on female respondents.

11. The sample in the models including the work status covariate comprises only 1,151 women; 70 cases with missing data on the work history had to be excluded.

12. The educational attainment of respondents is introduced in the model as a fixed rather than time-varying covariate because almost all but 9 respondents (i.e., 1.8 per cent of the sample) had completed their schooling by the time they experienced their first stepfamily episode.

13. We also ran models that included mother tongue, religion, as well as interaction terms between region and mother tongue and region and religion, but none of these variables turned out to be statistically significant. They were thus excluded from the analysis. 
Unfortunately, no information on other socioeconomic characteristics, such as income, was collected retrospectively in the survey and can be included into our analysis.

\section{Method}

We use Cox proportional hazard models to simultaneously assess the effect of a series of timeconstant and time-varying covariates on the hazard (or conditional probability) of giving birth to a child in a stepfamily (Blossfeld et al. 2007). The duration of the stepfamily episode at the child's birth is established by subtracting the age at the beginning of union from the age of respondents at birth. The episodes are censored 1) if the stepfamily was still ongoing and without a common child at the time of the survey, or 2) when the woman reached the age of 43,3 ) when the couple separated or the partner died, or 4) when the last stepchild left home.

To examine the impact of the stepfamily composition on fertility, we estimate three sets of models. The first set controls only for the number of children present at the beginning of the stepfamily episode, irrespective of whose children those are. The second set of models distinguishes stepfamilies in which both partners have children from previous relationships from those in which only the man or only the woman has child/children. Finally, the third set of models considers the stepfamily composition in more details; it controls not only for the man's and woman's parental status but also for the number of children each of them has.

Sample weights are used to adjust for the stratified and clustered design of the survey in the descriptive statistics. We further use the bootstrap weights provided by Statistics Canada in the Cox models in order to obtain unbiased and accurate estimates of variance. The results presented below reflect the standard errors derived from re-sampling each model 200 times.

\section{Results}

\section{Descriptive statistics}

Table 1 presents the distribution of the independent variables included in the multivariate analysis, according to the respondent's gender. This table reveals large discrepancies in the reports made by men and women. The large majority ( 83 per cent) of stepfamily episodes reported by women comprise a mother living with her own children and a stepfather. In contrast, the stepfamily episodes identified from male respondents' reports are more equally distributed according to the children's origin. Only half of these episodes involve a man living solely with a partner and her children; roughly 40 per cent comprise a man living with his children and a stepmother, and nearly 10 per cent a man and a woman who both have children from previous unions.

Two reasons might be invoked to account for the observed discrepancies. Part of the difference might be attributable to the tendency of men to underreport children with whom they no longer live, including stepchildren. This tendency generally results in an overrepresentation of ongoing family episodes and of involved fathers who reside or have close relationships with their children in the male samples gathered in retrospective surveys (for a discussion, see Joyner et al. 2012; Juby and Le Bourdais 1999; Rendall et al. 1999; Toulemon and Lapierre-Adamcyk 1995). The fact that the number of women involved in the stepfamily episodes identified in the GSS sample is nearly twice that of men suggests the existence of such selection effect. Second, part of the difference between male and female reports might be due to the way in which the GSS collected information on respondents' stepchildren. As mentioned earlier, the GSS did not collect information on the parental histories of 
Table 1. Descriptive statistics (\% or means) ${ }^{1}$ for covariates used in analysis, according to respondent gender.

\begin{tabular}{|c|c|c|c|}
\hline \multirow{2}{*}{ Variables } & \multicolumn{3}{|c|}{ Respondent gender } \\
\hline & Male & Female & All Respondents \\
\hline \multicolumn{4}{|l|}{ Composition of the stepfamily $\left(\chi^{2}=230.97 \mathrm{p}=.000\right)$} \\
\hline Only the man has children (stepmother) & 40.5 & 13.5 & 24.3 \\
\hline Only the woman has children (stepfather) & 49.7 & 82.6 & 69.4 \\
\hline Both man \& woman have children (stepmother/stepfather) & 9.8 & 3.9 & 6.3 \\
\hline \multicolumn{4}{|l|}{ Woman's number of children at the beginning of the episode } \\
\hline$(\chi 2=178.84 \mathrm{p}=.000)$ & 40.5 & 13.5 & 24.3 \\
\hline$\pi$ & 33.9 & 48.7 & 42.7 \\
\hline $2+$ & 25.6 & 37.8 & 32.9 \\
\hline \multicolumn{4}{|l|}{ Man's number of children at the beginning of the episode } \\
\hline$(\chi 2=229.77 \mathrm{p}=.000)$ & 49.7 & 82.5 & 69.4 \\
\hline 1 & 27.2 & 10.0 & 16.9 \\
\hline $2+$ & 23.1 & 7.5 & 13.7 \\
\hline \multicolumn{4}{|l|}{ Age at beginning of the episode, woman $\left(\chi^{2}=10.79 p=.013\right)$} \\
\hline Less than 25 years & 28.2 & 31.4 & 30.1 \\
\hline $25-29$ years & 29.5 & 23.2 & 25.7 \\
\hline $30-39$ years & 19.9 & 23.2 & 21.9 \\
\hline 40 years and older & 22.4 & 22.2 & 22.3 \\
\hline Mean age (in years) & 29.3 & 29.2 & 29.3 \\
\hline \multicolumn{4}{|l|}{ Age at beginning of the episode, man $\left(\chi^{2}=0.12 \mathrm{p}=.990\right)$} \\
\hline Less than 25 years & 20.5 & 20.3 & 20.4 \\
\hline 25-29 years & 22.7 & 22.6 & 22.7 \\
\hline $30-34$ years & 22.3 & 21.8 & 22.0 \\
\hline 35 years and older & 34.5 & 35.2 & 34.9 \\
\hline Mean age (in years) & 32.1 & 32.5 & 32.3 \\
\hline \multicolumn{4}{|l|}{ Man's age relative to his partner $(\chi 2=5.84 \mathrm{p}=.054)$} \\
\hline Man 5 years or more older & 30.7 & 32.0 & 31.5 \\
\hline In between 5 years older and 2 years younger & 49.0 & 52.0 & 50.8 \\
\hline Man 2 years or more younger & 20.3 & 16.0 & 17.7 \\
\hline \multicolumn{4}{|c|}{ Number of children at the beginning of the episode $\left(\chi^{2}=3.21 \quad \mathrm{p}=.200\right)$} \\
\hline 1 & 51.3 & 53.8 & 52.8 \\
\hline 2 & 35.1 & 31.2 & 32.8 \\
\hline 3 and more & 13.6 & 15.0 & 14.4 \\
\hline Average number of children & 1.70 & 1.67 & 1.68 \\
\hline \multicolumn{4}{|c|}{ Age of youngest child at the beginning of the episode $\left(\chi^{2}=2.13 p=.345\right)$} \\
\hline younger than 5 & 44.4 & 47.6 & 46.3 \\
\hline 5-11 years & 42.0 & 40.5 & 41.1 \\
\hline 12 and older & 13.6 & 12.0 & 12.6 \\
\hline Average age of youngest child (in years) & 6.4 & 6.1 & 6.2 \\
\hline \multicolumn{4}{|l|}{ Type of union ${ }^{2}\left(\chi^{2}=1.95 \mathrm{p}=.163\right)$} \\
\hline Marriage & 39.0 & 42.3 & 41.0 \\
\hline Cohabiting union & 61.0 & 57.7 & 59.0 \\
\hline \multicolumn{4}{|l|}{ Rank of union $\left(\chi^{2}=21.54 \mathrm{p}=.000\right)$} \\
\hline 1 & 45.8 & 35.7 & 39.7 \\
\hline 2 & 49.8 & 60.6 & 56.3 \\
\hline 3 and more & 4.4 & 3.7 & 4.0 \\
\hline \multicolumn{4}{|l|}{ Period of beginning of the episode ${ }^{2} \quad\left(\chi^{2}=20.29 p=.000\right)$} \\
\hline Before 1970 & 7.8 & 13.4 & 11.2 \\
\hline $1970-1979$ & 15.9 & 16.7 & 16.4 \\
\hline 1980-1989 & 26.8 & 28.8 & 28.0 \\
\hline 1990 and after & 49.4 & 41.1 & 44.4 \\
\hline \multicolumn{4}{|l|}{ Region $\left(\chi^{2}=3.00 \mathrm{p}=.083\right)$} \\
\hline Quebec & 28.2 & 24.6 & 26.0 \\
\hline Elsewhere in Canada & 71.8 & 75.4 & 74.0 \\
\hline Education $\left(\chi^{2}=17.74 \mathrm{p}=.000\right)$ & & & \\
\hline Less than high school & 23.8 & 27.3 & 25.9 \\
\hline High school diploma & 25.1 & 25.8 & 25.5 \\
\hline College degree & 34.7 & 36.8 & 36.0 \\
\hline University degree & 16.5 & 10.0 & 12.6 \\
\hline Work status $^{2}$ & & & \\
\hline Never worked & & 17.8 & \\
\hline Not working & & 11.1 & \\
\hline Working & & 64.6 & \\
\hline Missing data & & 6.5 & \\
\hline $\begin{array}{l}\mathrm{N} \\
\%\end{array}$ & $\begin{array}{r}658 \\
35.0\end{array}$ & $\begin{array}{r}1221 \\
65.0\end{array}$ & $\begin{array}{r}1879 \\
100.0\end{array}$ \\
\hline
\end{tabular}

Source: Statistics Canada, 2001, General Social Survey (Cycle 15) on Family.

${ }^{1}$ Percentages and means based on weighted data. The percentages sum up vertically.

${ }^{2}$ Value taken at the beginning of the episode for time-varying covariates. 
respondents' current and previous partners, but rather asked respondents if they had ever 'raised' any stepchildren. Given that fathers are much less likely than mothers to live on a regular basis with their children following separation or divorce, it is quite probable that women who formed a union with a man who had children who were not residing with him did not consider 'raising' their partner's children. This could account in part for the relatively low percentage of women who reported acting as a stepmother.

The average number of children identified at the beginning of the episodes is 1.68; approximately one family out of two counts only one stepchild, and nearly one in seven comprises three or more children. The reported number of children that mothers and fathers brought into the family differs depending on the gender of the respondent. Men's number of pre-union children is higher when reported by male rather than by female respondents; for example, 23.1 per cent of men mentioned having two or more children, but only 7.5 per cent did so according to women's reports. Similarly, a larger proportion of women are found to have two or more children from previous relationships based on females' rather than males' reports (37.8 versus 25.6 per cent).

Women were, on average, three years younger than men at the beginning of the stepfamily episode (29 years as compared to 32 years). In approximately half of the cases, the man was between two years younger and five years older than his partner; for slightly less than a third of the episodes, the man was five or more years older, and for 18 per cent, the woman was two or more years older (the percentage is slightly higher, reaching 20 per cent, among the episodes reported by males). Nearly half of the stepfamilies were formed by an individual whose youngest child was under 5 years of age; the youngest child was 12 years or older in only 13 per cent of cases.

The majority (59.0 per cent) of couples were cohabiting at the beginning of the stepfamily episode. For over half (56.3 per cent) of respondents, the stepfamily episodes constituted their second union. However, a higher fraction of male respondents reported that they were in their first union, a result that could be linked to the incomplete report of past unions by men, as found in previous studies. This also probably accounts, in part, for the larger proportion of episodes reported by men which started in 1990 of later. Approximately a quarter of respondents who experienced stepfamily life resided in Quebec. A quarter of respondents did not complete high school, and approximately half this percentage received a university degree (12.6 per cent), with more men doing so than women.

Table 2. Cumulative proportions of stepfamily couples who have given birth at given duration, according to family composition and respondent's gender (Life Table estimates).

\begin{tabular}{lcccc}
\hline \multirow{2}{*}{$\begin{array}{c}\text { Years since } \\
\text { beginning of the } \\
\text { episode }\end{array}$} & $\begin{array}{c}\text { Only man } \\
\text { has children }\end{array}$ & $\begin{array}{c}\text { Only woman } \\
\text { has children }\end{array}$ & $\begin{array}{c}\text { Both man \& } \\
\text { woman have } \\
\text { children }\end{array}$ & All stepfamilies \\
\hline $\begin{array}{c}\text { Female Respondents } \\
1\end{array}$ & 0.19 & 0.13 & 0.12 & 0.14 \\
3 & 0.49 & 0.36 & 0.34 & 0.37 \\
5 & 0.59 & 0.45 & 0.43 & 0.47 \\
10 & 0.63 & 0.51 & 0.43 & 0.53 \\
Male Respondents & & & & \\
1 & 0.14 & 0.12 & 0.06 & 0.12 \\
3 & 0.32 & 0.39 & 0.18 & 0.34 \\
5 & 0.47 & 0.49 & 0.24 & 0.45 \\
10 & 0.55 & 0.58 & 0.24 & 0.53 \\
\hline
\end{tabular}

Source: Statistics Canada, 2001, General Social Survey (cycle 15) on Family. 
Finally, nearly one woman out of five had never worked before the beginning of the stepfamily episode, and two-thirds of women were working at that time.

Table 2 shows the cumulative proportion of stepfamily couples who have given birth to a child at given duration, according to the respondent's gender. Ten years after the beginning of the episode, approximately half of the stepfamily couples had given birth, and the proportion reported by men and women is similar. The probability that couples have a child together does, however, vary in relation with the family composition. According to women's reports, couples in which only the man had children from a previous union are the most likely to have a child together: over 60 per cent of them had done so ten years after the beginning of the union, compared to 51 per cent when only the woman had children and 43 per cent when both of them had children. The picture is slightly different from men's point of view. In this case, both stepfamilies in which only the man or only the woman has children have relatively similar cumulated probabilities of giving birth: 55 and 58 per cent respectively. One should note that the pace of giving birth is relatively rapid: three years after the beginning of the episode, approximately two-thirds of the couples who give birth within ten years have already done so.

\section{Factors associated with childbearing}

Given the high discrepancy observed between female and male reports, we estimated Cox models separately by gender (see Table 3). Model 1 measures the stepfamily composition solely according to the number of children present at the beginning of the union. The effect of the number of children considerably differs depending on whether the episode was reported by a man or a woman. The analysis shows that the total number of children does not influence the risk of having a common child among stepfamilies reported by women when other relevant factors are controlled for. This result corroborates that established in previous research based predominantly on female samples. However, the number of children does exert a strong and negative effect on fertility among male respondents: stepfamily couples with three or more children have only a third of the risk of having a common child compared to those with only one child. In other words, according to men's reports, the risk of having a common child is particularly low when two children are already present in the stepfamily.

Model 2 uses a different measure of the stepfamily composition that separates families according to the man's or woman's parental status, i.e. that distinguishes stepfamilies depending on whether only the man, only the woman or both partners brought children into the union. Again, the estimated risk of childbearing differs dramatically between the two samples. The results based on the female subsample show that the risk of having a common child is significantly higher if the woman is childless, i.e. if only the man has children. According to women's reports, stepfamily couples comprising a childless woman have a 39 per cent higher risk of giving birth to a child than those in which the man is childless; when both partners brought children into the stepfamily, the risk of having a common child is not significantly different from that observed when only the woman has pre-union children. In contrast, men's reports suggest that the risk of childbearing is the lowest when both partners have children. When only the man has children, the risk of stepfamily couples to give birth to a child is not significantly lower than that of couples comprising a childless man (the reference category), but it is reduced by 60 per cent when both partners have children.

Lastly, Model 3 incorporates detailed measures of family composition based on the number of pre-union children and whose children those are. According to women's reports, the risk of childbearing is significantly higher in one-child stepfamilies, but only when the woman is childless. This type of family has a 65 per cent higher risk of having a common child compared to those in which 


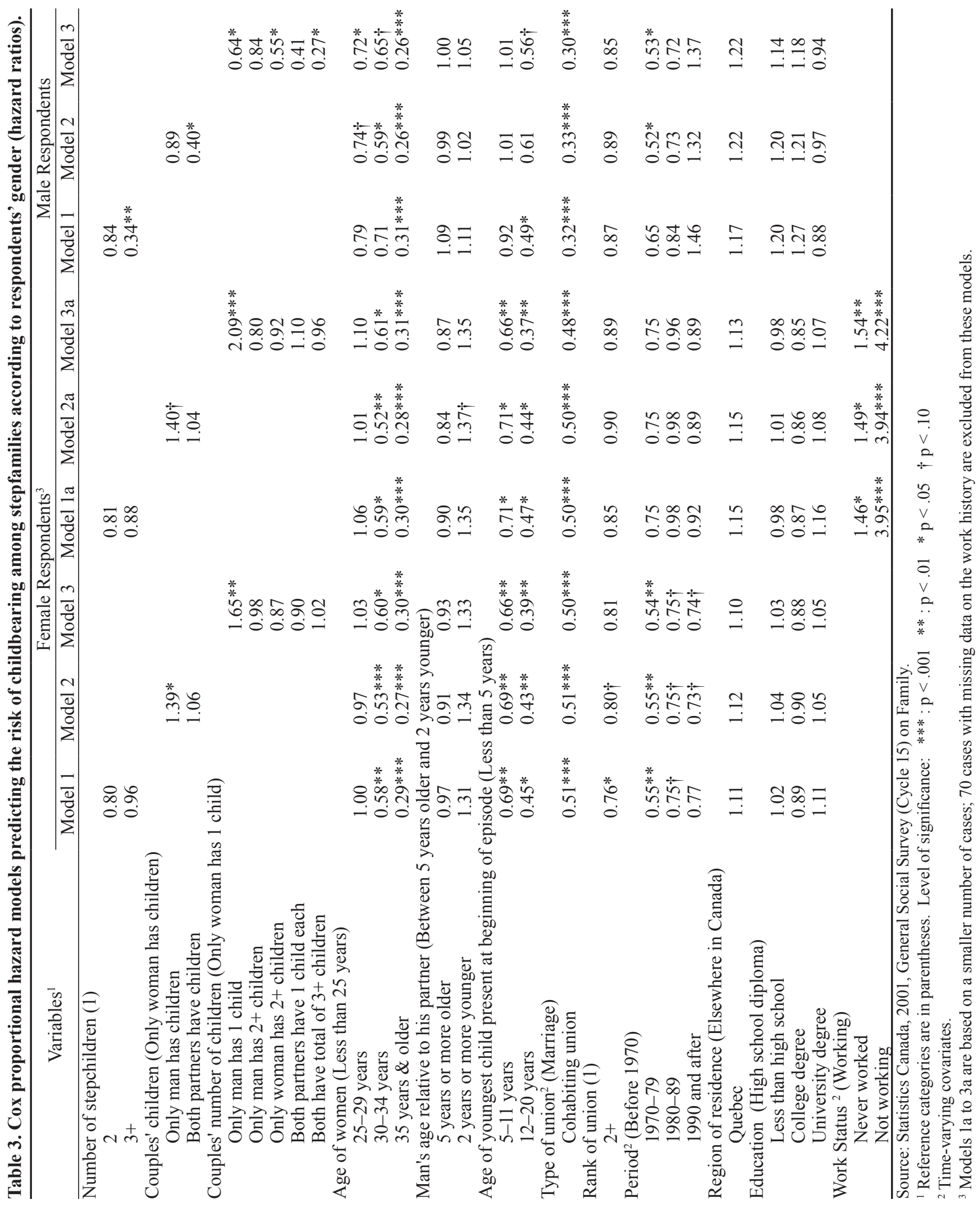


solely the woman has one child (reference category). However, woman's childlessness does not appear to be associated with a higher risk of childbearing when the man has two or more children. In contrast, results from the men's subsample indicate that the risk of having a common child tends to be more closely related to the number of children in the family. Hence, the highest risk of childbearing is found among one-child families in which only the woman has a child, and the lowest risk among the stepfamilies comprising three or more children (from both partners), with the latter having a 73 per cent lower risk of having a child than the former. When only the man has one pre-union child or when solely the woman has two or more children, the risk of giving birth to a child is reduced by approximately 35 to 45 per cent, compared to that of families in which only the woman is the parent of one child. Similarly to Model 2, the effect of male childlessness thus appears to be stronger than the effect of female childlessness in the male subsample.

Regarding the other covariates, the effects of the woman's age and of the type of union seem to be consistent in both subsamples. The risk of having a common child significantly increases when the couple is married and decreases when the woman reaches the age of 30, irrespective of whether the stepfamily episode was reported by a man or woman. Hence, cohabiting couples have half the risk of married couples to have a child together in the female subsample, and approximately a third of that risk in the male subsample. Compared to women who were younger than 25 at the formation of the stepfamily, those aged 30-34 and 35 years and over see their risk of giving birth reduced approximately by 40 and 70 per cent respectively; in the male subsample, women aged 25-29 years also appear to be less likely to have a child than their younger counterparts. These results are not surprising given the large body of literature that has documented the effect of female age and type of union on fertility.

Further, female reports suggest that the risk of giving birth to a child is slightly higher when a woman partners with a man who is 2 years or more younger than she is (around 35 per cent, marginally significant when the woman's work status is taken into account); however, no such effect of age differences is observed in the male sample. Similarly, the effect of the age of the youngest child present at the beginning of the family episode appears to more closely affect the risk of childbearing in the female rather than in the male sample. As expected, even after controlling for the woman's age and the stepfamily composition, women are less likely to give birth to a child if the youngest child is 5 years or older; those whose youngest child in the family is aged 5-11 years have roughly two-thirds the risk of women living with preschoolers to give birth to a child, and those whose youngest child is between 12-20 years 40 per cent that risk to do so. By comparison, only when the youngest child is older than 11 years are stepfamily couples significantly less likely to have a child together from the male's point of view. The effect of the rank of the union, which was found to be statistically significant in the female sample when controlling only for the number of children present at the beginning of the episode, becomes non-significant (as in the male sample) when the family composition is included in the model.

Gender inconsistencies are also observed regarding the effect of the time period. The estimates based on female reports suggest that the pre-1970s was a period characterized by particularly high risks of childbearing among stepfamilies: women who experienced stepfamily life in the three following decades all have lower risks of giving birth than the former, approximately 50 per cent lower for those who did so in the 1970s and 25 per cent lower for those who did so later on. In the male subsample, only the stepfamily couples living through the 1970s faced a significantly lower risk of having a common child, compared to the reference group. Finally, our analysis did not confirm the expectation that the birth of a common child would be significantly associated with the respondents' region of residence or levels of education. 
Models $1 \mathrm{a}$ to $3 \mathrm{a}$ further include the labour force participation of women into the analysis, after excluding cases with missing data on this variable. ${ }^{14}$ Two conclusions can be drawn from these models. First, taking into account the employment status of women during the course of the episode does not substantially change the effect of the family composition or the effect of any of the other covariates except for that of the period. Clearly, the fact that the lower risk of having a common child past 1970 in the female sample is no longer significant when controlling for women's presence in the labour market is linked to the changes in female employment that started occurring during the 1970s. Second, the effect of the employment status itself appears to be strong and statistically significant. On one hand, women who have never worked have a 50 per cent higher risk of having a common child than those who are working. On the other hand, women experiencing a work interruption have approximately four times the risk of giving birth to a child during the stepfamily episode than those who remain in the labour force.

\section{Discussion}

Despite the growing interest in stepfamilies and fertility behaviours following conjugal separation, the effect of the number of stepchildren present in the family remains unclear and Canadian studies focusing on these topics remain rare. This paper aimed to fill this gap by examining the arrival of a common child in stepfamilies using the 2001 Canadian GSS. Unlike previous work, this article directly focused on the effect of women's labour force participation and analysed stepfamilies reported by both male and female respondents. The analysis revealed that approximately half of the stepfamily couples have given birth to a child within ten years of the beginning of their union. It showed that the probability of childbearing is linked to the age of the woman, the type of union, as well as the employment status of women, the birth of a child being more likely to occur among younger women, married couples and women who were outside the labour market.

One of the most striking results of our study is the dramatic difference observed in the effects of family composition on childbearing depending on the respondents' gender. In general, the results based on the female subsample corroborate the findings of past research which suggest that the number of children in the stepfamily does not in itself influence the risk of having a common child. Instead, the detailed composition of the family must be taken into consideration. When taking such an approach, the analysis based on the female subsample indicated that women's childlessness is a more important determinant of childbearing in stepfamilies than that of men, as recent research has shown. In contrast, male reports suggested that the man's past fertility is as, if not more, important than that of the woman and that the number of pre-union children matters. Hence, the results observed from the women's point of view would tend to corroborate the hypothesis relative to the strong value of the birth of a child in that it confers the status of parenthood on women and legitimates them in a maternal role. Those based on male reports instead tend to confirm the idea that the birth of a common child is of special value, that it reveals a sign of commitment to the union by both partners.

Past research has often disregarded as unreliable men's responses in surveys and focused solely on female respondents (for example, see Teachman 2008; Vikat et al. 2004). However, we argue that this practise might be unsatisfactory and that the inclusion of men into the analysis might shed some light on some potential biases in the results based on female responses due to data collection. In addition, the discrepancies observed between males' and females' responses may well reflect something

14. Models 1 to 3 were re-estimated using this subsample and did not reveal any significant changes in the coefficients. 
Heintz-Martin et al.: Childbearing among Canadian stepfamilies

other than just men's misreports and point out to gender differences in the way that stepparenthood and stepfamily life are experienced. Given the fact that children are more likely to stay with their mothers after their parents' separation, the large majority of the stepfamily episodes observed in the female subsample are defined simply by the arrival of a new partner into the woman's household, irrespective of his 'parental' involvement with her children. In other words, the role of stepfather is automatically assigned to any man who forms a conjugal relation with a woman living with her children. In contrast, the stepfamilies identified from the male sample count a relatively large fraction of families in which men live with their own children, that is, of involved fathers who have close relationships with their children, and some men who have taken on the role of the stepfather. The fact that the number of male respondents involved in a stepfamily episode is nearly half that of the female respondents clearly reveals the existence of such selection effect.

The differences observed in the distribution of family types according to the respondents' gender carry important repercussions for the analysis of fertility in stepfamilies. The findings derived from the male subsample suggest, as we have seen, that males' past fertility might be as, if not more, important a determinant of childbearing than that of the woman. This could be related to the fact that the male stepfamily sample includes a large proportion of "involved" fathers, a situation that would encourage women to have children with these partners. Hence, the impact of men's past fertility could be more important than that of females in such family environments. The discrepancy observed according to respondents' gender also puts into question the standard practise in stepfamily research that implicitly assumes that the partner living with the mother takes on an active role as a stepfather to her children. It is possible that the lack of effect of males' past fertility on childbearing found in the female sample simply reflects the fact that a large number of these men are engaged in a conjugal relationship but not in any parental role. Clearly, more research is needed in order to better understand childbearing intentions and behaviours among Canadian stepfamilies.

\section{Acknowledgment}

This paper builds on Valerie Martin's (2008) Ph.D. dissertation, "Stepfamilies in Canada: Numbers, characteristics, stability and childbearing". Support for this research was provided by the Social Sciences and Humanities Research Council of Canada, the McGill Canada Research Chair on Social Statistics and Family Change, the German Academic Exchange Service (DAAD) and the Czech Science Foundation project P404/11/0145. The authors thank Paul-Marie Huot for his assistance with data construction and analysis. The results are based on analyses conducted at the Quebec Interuniversity Centre for Social Statistics (QICSS) which provides researchers access to the microdetailed data collected by Statistics Canada. The opinions expressed here, however, are theirs alone. The authors are grateful to the reviewers for their helpful comments.

\section{References}

Ambert, A.M. 1986. Being a stepparent: Live-in and visiting stepchildren. Journal of Marriage and the Family 48(4):795-804.

Beaujouan, E., and A. Solaz. 2008. Childbearing after separation: Do second unions make up for earlier missing births? Evidence from France. Paris: INED, Documents de travail № 155.

Blossfeld, H-P., K.S. Golsch, and G. Rohwer. 2007. Event History Analysis with STATA. Mahwah (N.J.) and London: Lawrence Erlbaum. 
Bohnert, N. 2011. Examining the determinats of union dissolution among married and common-law unions in Canada. Canadian Studies in Population 38(3-4):75-92.

Brewster, K.L., and R.R. Rindfuss. 2000. Fertility and women's employment in industrialized nations. Annual Review of Sociology 26:271-296.

Brown, S.L. 2000. Fertility following marital dissolution: The role of cohabitation. Journal of Family Issues 21(4):501-524.

Buber, I., and A. Prskawetz. 2000. Fertility in second unions in Austria: Findings from the Austrian FFS. Demographic Research 3(2):1-44.

Bumpass, L. 1984. Some characteristics of children second families. American Journal of Sociology 90(3):608-623.

Desrosiers, H., C. Le Bourdais, and B. Laplante. 1995. Les dissolutions d'union dans les familles recomposées: l'expérience des femmes canadiennes. Recherches sociographiques 36(1):47-64.

Goldscheider, F.K., and G. Kaufman. 1996. Fertility and commitment: Bringing men back in. Population and Development Review 22(supplement):87-99.

Griffith, J.D., H.P. Koo, and C.M. Suchindran. 1985. Childbearing and family in remarriage. Demography 22(1):73-88.

Henz, U. 2002. Childbirth in East and West German stepfamilies: Estimated probabilities from hazard rate models. Demographic Research 7(6):307-342.

Jefferies, J., A. Berrington, and I. Diamond. 2000. Childbearing following marital dissolution in Britain. European Journal of Population 16(3):193-210.

Joyner, K., H.E. Peters, K. Hynes, A. Sikora, J. Rubenstein Taber, and M.S. Rendall. 2012. The quality of male fertility data in major U.S. surveys. Demography 49(1):101-124.

Juby, H., and C. Le Bourdais. 1999. Where have all the children gone? Comparing mothers' and fathers' declarations in retrospective surveys. Canadian Studies in Population 26(1):1-20.

Juby, H., N. Marcil-Gratton, and C. Le Bourdais. 2001. A step further in family life: The emergence of the blended family, in Report on the Demographic Situation in Canada 2000, edited by A. Bélanger. Ottawa: Statistics Canada, Cat. n 91-209: 169-203, pp.

Lapierre-Adamcyk, É., and C. Le Bourdais (coll. V. Martin and P.M. Huot), 2008. La diversification de la structure et de la composition des familles an Canada, Montreal: Final Report submitted to Human Ressources and Social Development Canada.

Le Bourdais, C., M. Girard, L. Swiss, and É. Lapierre-Adamcyk. 2013. Entre famille et vieillissement: Impact des transformations familiales aux âges avancés. International Journal of Canadian Studies / Revue internationale des études canadiennes 47:9-40.

Le Bourdais, C., and É. Lapierre-Adamcyk. 2011. Mariage et union libre. Quelques indicateurs sociodémographiques. Paper presented at the conference Lola c. Éric, de l'union libre au mariage de fait? La pension alimentaire au conjoint après l'union libre. Montréal: INRS Urbanisation, Culture et Société, April.

- 2004. Changes in conjugal life in Canada: Is cohabitation progressively replacing marriage? Journal of Marriage and Family 66(4):929-942.

Li, J.-C.A. 2006. The institutionalization and pace of fertility in American stepfamilies. Demographic Research 14(12):237-266. 
Heintz-Martin et al.: Childbearing among Canadian stepfamilies

Martin, V. 2008. Stepfamilies in Canada: Numbers, Characteristics, Stability and Childbearing. [PhD-Thesis]. Montreal: McGill University, Department of Sociology.

Martin, V., C. Le Bourdais, and É. Lapierre-Adamcyk. 2011. Stepfamily instability in Canada: The impact of family composition and union type. Journal of Family Research 23(2):196-218.

Prskawetz, A., A. Vikat, D. Philipov, and H. Engelhardt. 2002. Pathways to Stepfamily Formation in Europe: Results from the FFS. Rostock: Max Planck Institute for Demographic Research (MPRIDR working paper; WP 2002-046).

Rendall, M.S., L. Clarke, H.E. Peters, N. Ranjit, and G. Verropolou. 1999. Incomplete reporting of men's fertility in the United States and Great Britain: A Research Note. Demography 36(1):135-144.

Statistics Canada. 2001. General Social Survey, Cycle 15: The Family. Public Use Microdata File Documentation and User's Guide. Ottawa: Statistics Canada.

- 2001. Contemporary American stepparenthood: Integrating cohabiting and nonresident stepparents. Population Research and Policy Review 20(4):345-364.

Stewart, S.D. 2002. The effect of stepchildren on childbearing intentions and births. Demography 39(1):181-197.

Sweeney, M.M. 2010. Remarriage and stepfamilies: Strategic sites for family scholarship in the twentyfirst century. Journal of Marriage and Family 72(3):667-684.

Teachman, J.D. 2008. Complex life course patterns and the risk of divorce in second marriages. Journal of Marriage and Family 70(2):294-305.

Thomson, E. 1997. Her, his and their children: Influences on couples childbearing decisions. Madison: National Survey of Families and Households, Working Paper \# 76, Center for Demography and Ecology, University of Wisconsin-Madison.

- 2004. Step-families and childbearing desires in Europe. Demographic Research 3(5):116-134.

Thomson, E. and Li, J-C. A. 2002. Her, his and their children: Childbearing intentions and birth in stepfamilies. Wisconsin: University of Wisconsin (NSFH working paper \# 89).

Toulemon, L. 1997. The fertility of step-families: The impact of childbearing before the current union. Paper presented at the The Annual Meeting of Population Association of America. Washington, March.

Toulemon, L., and É. Lapierre-Adamcyk. 1995. Demographic patterns of motherhood and fatherhood in France. Paper presented at the USSP Anthropology and Demography Committee Seminar on Fertility and the Male Life Cycle. Zacatecas, November.

Vikat, A., E. Thomson and J.M. Hoem. 1999. Stepfamily fertility in Contemporary Sweden: The Impact of childbearing before the current union. Population Studies 53(1):271-279.

Vikat, A., E. Thomson, and A. Prskawetz. 2004. Childrearing responsibility and stepfamily fertility in Finland and Austria. European Journal of Population/Revue européenne de Démographie 20(1):1-21.

Wineberg, H. 1990. Childbearing after remarriage. Journal of Marriage and Family 52(1):31-38.

. 1992. Childbearing and dissolution of the second marriage. Journal of Marriage and Family 54(4):879-887.

Wu, Z., and C.M. Schimmele. 2003. Childhood family experience and completed fertility. Canadian Studies in Population 30(1):221-240. 